\title{
30. DIAGENESIS OF ORGANIC MATTER AND ESTIMATED TEMPERATURE HISTORY FROM CARBONIZATION MEASUREMENTS, SHIKOKU BASIN
}

\author{
R. L. Ames and R. Littlejohn, Amoco Production Company, Tulsa, Oklahoma
}

\section{INTRODUCTION}

Core samples have been analyzed from three holes off southeastern Japan (Figure 1). Five samples are from Hole 297 on the western edge of the Shikoku Basin immediately south of the Nankai Trough. Sixteen samples are from Holes 298 and 298A located on the inner slope of the Nankai Trough. The samples were analyzed to determine the organic content and to determine carbonization levels by elemental analysis, visual carbonization estimates, and palynomorph translucency measurements. The primary interest was in estimating the thermal history of the sediments.

The preliminary cruise report describes the stratigraphic section at Site 298 (Nankai Trough) as a turbidite sequence of early Pleistocene to Holocene age in which compaction, cleavage, and mesoscopic folding increase downward. The cleavage patterns suggest that the sediments have been deformed into a recumbent fold, presumably as a result of shearing along a subduction zone. Therefore, it is of interest to know whether the sediments had been buried more deeply prior to deformation, or whether they represent a "thinskinned" fold.

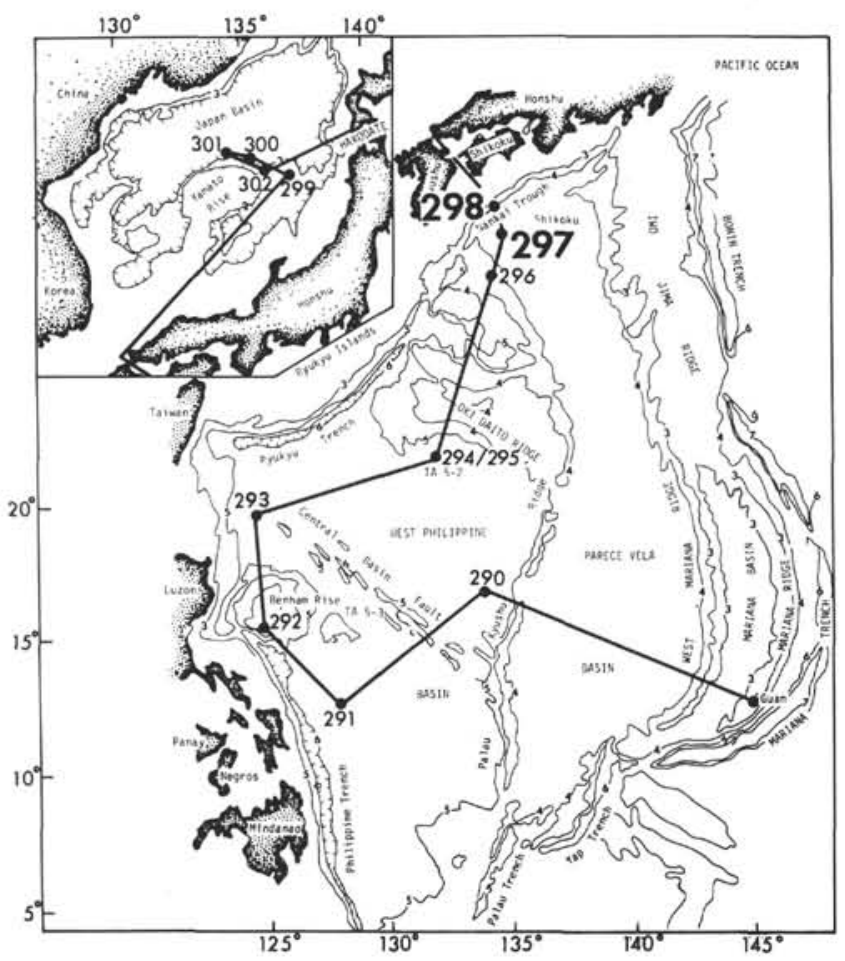

Figure 1. Location map for Sites 297 and 298.
The stratigraphic section at Site 297 (Shikoku Basin) consists of middle Miocene to Pleistocene age sediments. Presumably the pre-early Pliocene sediments were deposited before the initiation of the subduction zone along the Nankai Trough.

\section{DISCUSSION}

Organic carbon contents range from 0.2-0.6 wt \% (Table 1). Figure 2a shows the organic carbon content has only minor variation with depth in Hole 298. The small values may be due to partial oxidation of the organic matter in areas of slow deposition.

Most of the samples have extractable organic/total organic carbon ratios $<0.05$ (Table 1). The few samples with ratios exceeding 0.05 have a predominance of naphthenic versus paraffinic hydrocarbons which indicates the extracts are not oil-like; these extracts probably represent pipe dope contamination. Chromatographic analysis of the extracted hydrocarbons shows that samples in Hole 298 have pronounced odd-carbon predominance that is characteristic of immaturity (Figures 3-6). Persistence of the immature extracts to 600 meters depth indicates that there has been virtually no liquid hydrocarbon generation.

Elemental analysis of the kerogen in Hole 298 shows a fairly progressive increase in percent carbon, i.e., carbonization with depth (Figure 2b). Samples 175 and 176 have percent carbon values both above and below the apparent trend; the cause of these anomalous values is not known. The low $\mathrm{H} / \mathrm{C}$ ratios indicate that the kerogens are capable of generating only gaseous hydrocarbons.

R. Littlejohn has estimated the carbonization level of the kerogens, on a scale from 1 to 7 , by palynologic methods (Table 2). His values agree fairly well with those estimated by elemental carbon in the upper part of Hole 298; however, there is a discrepancy in the two deepest samples that may be related to the inferred recumbent fold. Visual analysis suggests that a lower carbonization zone is encountered between 217 and 567 meters, but this is not reflected in the elemental analyses. This ambiguity cannot be resolved from the present data.

Only two samples from Hole 297 had sufficient organic matter for elemental analysis (Table 2, Figure 7). Even though these sediments were older than any from Hole 298, the percent carbon of the kerogen is essentially the same at equivalent depths in both wells. This is confirmed by visual carbonization scale estimates. Therefore, both stratigraphic sections have experienced similar geothermal histories. 
TABLE 1

Insoluble Residue, Carbon, and Hydrocarbon Results, Holes 297, 298, and 298A

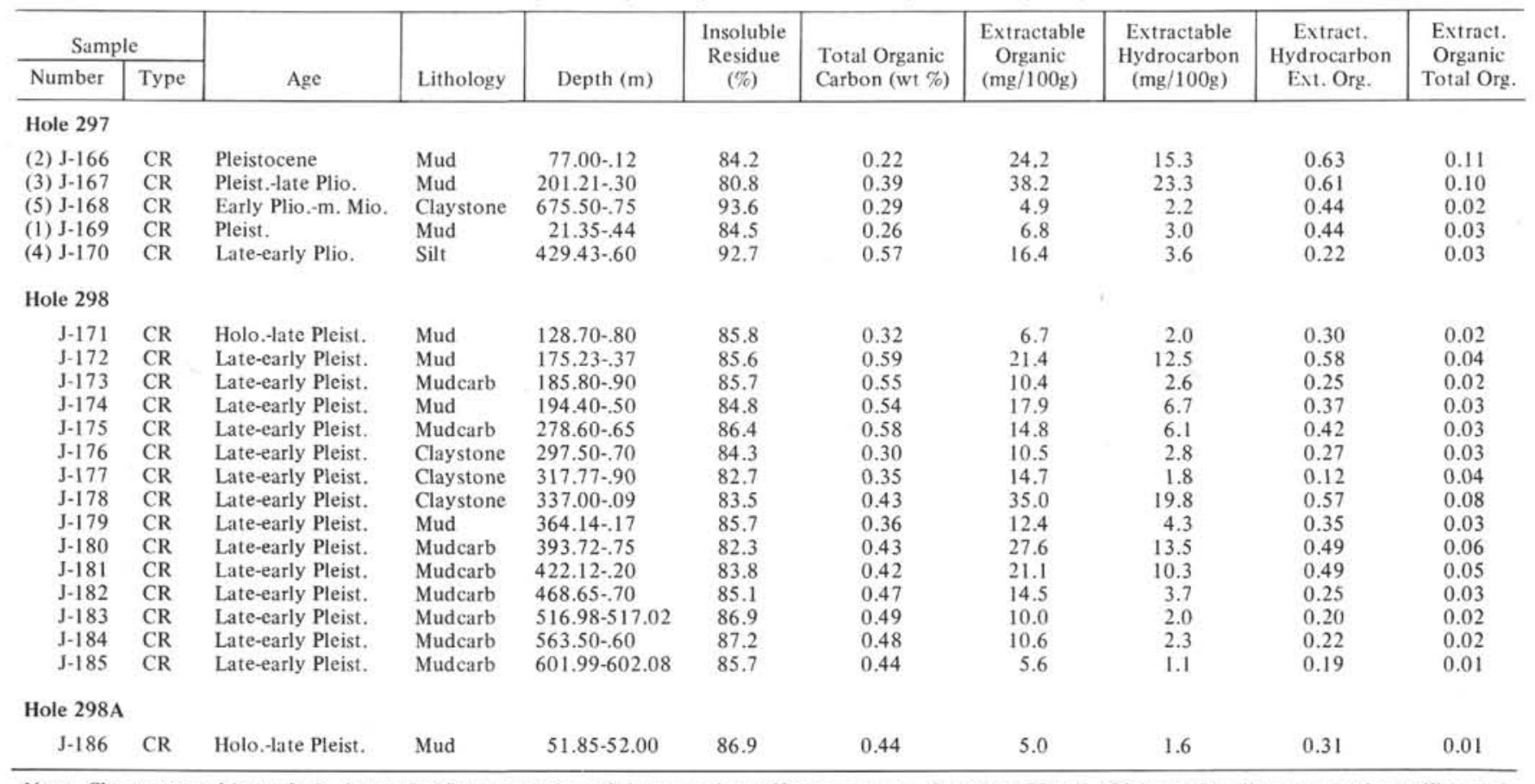

Note: Chromatographic analysis shows significant variation of the normal paraffin component. Samples 178 and 180 have virtually no normal paraffins. and these extracts may contain a contaminant such as pipe dope. The overall weak development of normal paraffins, or strong odd-carbon predominance of the $\mathrm{C}_{24}-\mathrm{C}_{30}$ paraffins. indicates very little liquid hydrocarbon generation.

HOLE 298

VISUAL CARBONIZATION SCALE
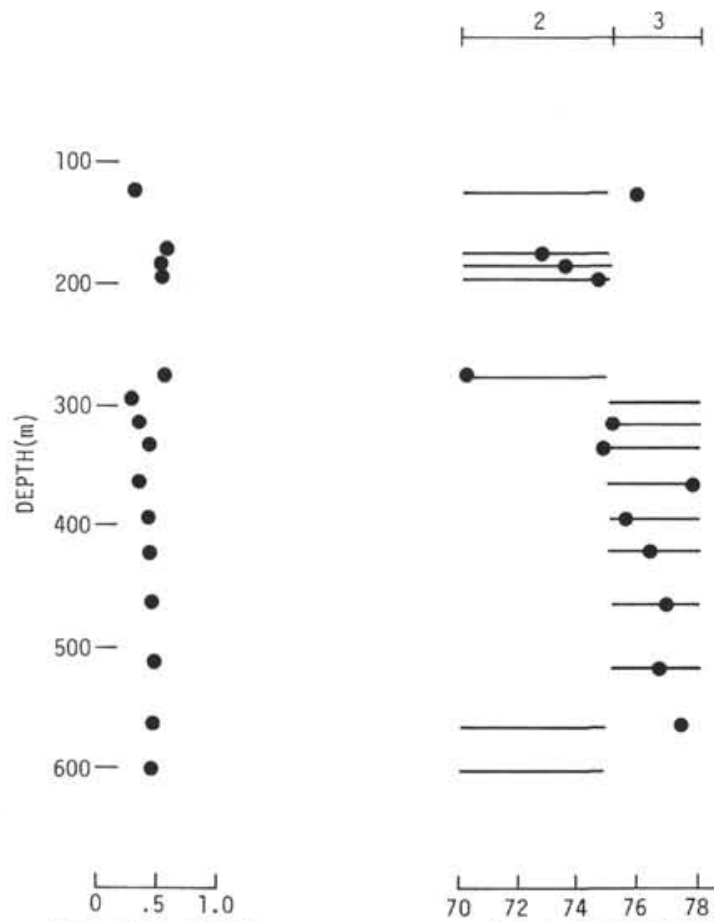

WT.\% ORG. CARBON

A. HYDROCARBON GEN. CAP.
It is apparent from the measurements of the diagenesis that the sediments have been subjected to a relatively mild geothermal history. Geochemical measurements cannot specify depth-temperature relationships because of the lack of experience with the peculiar, low-hydrogen-type kerogen encountered in these holes.

Figure 2. Hydrocarbon generation capability and state of diagenesis. Hole 298. 


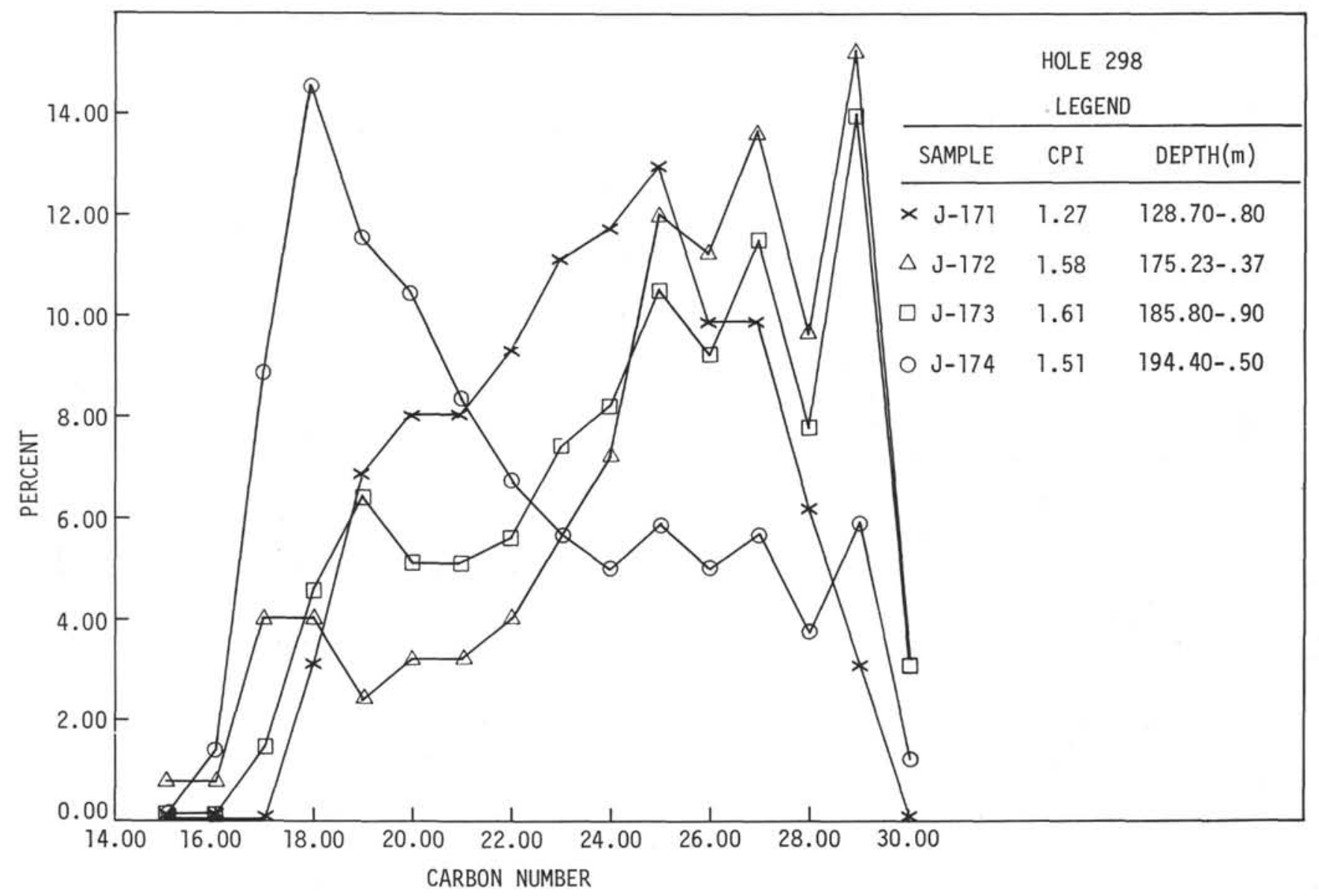

Figure 3. Heavy hydrocarbon distribution, Hole 298. 


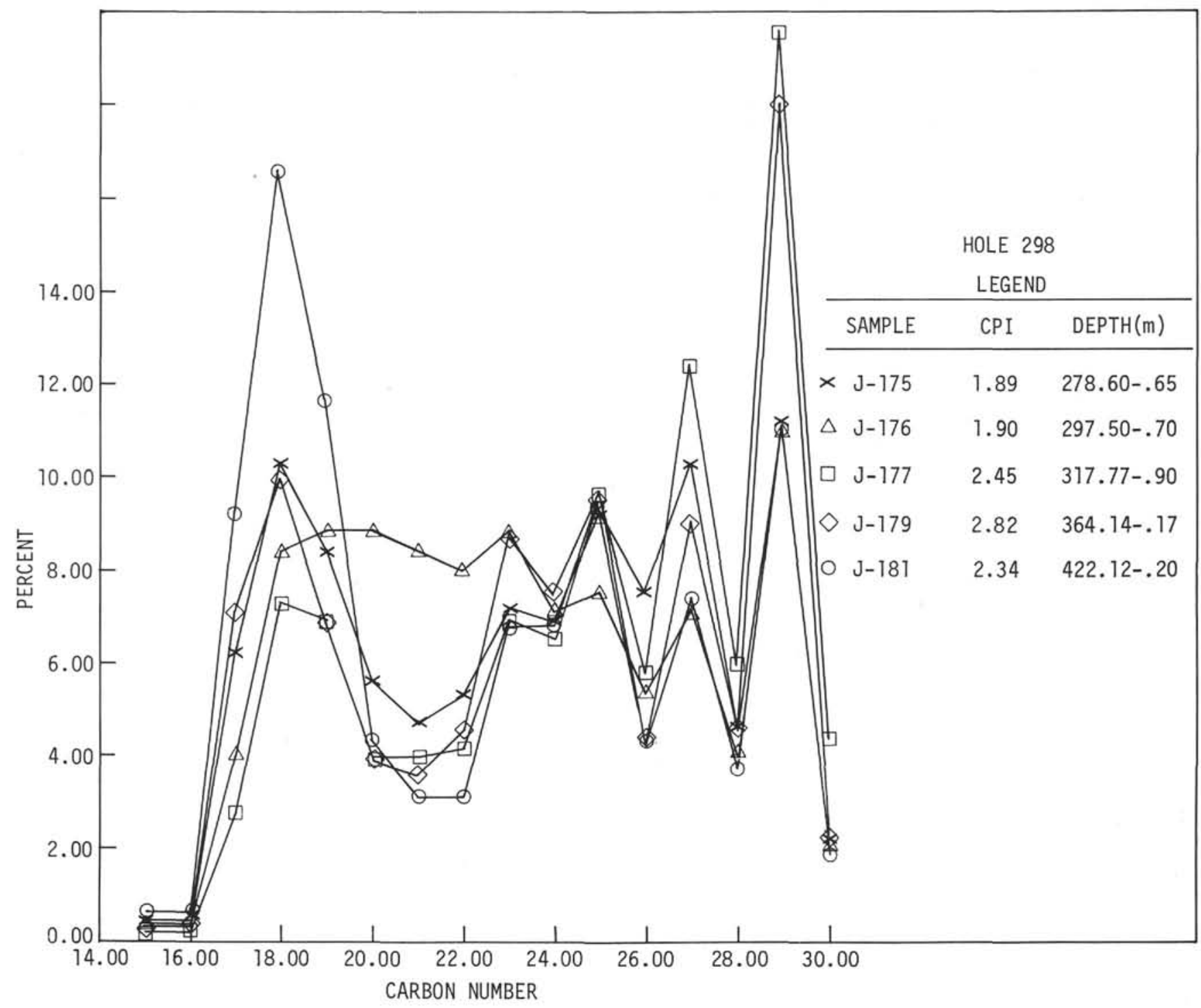

Figure 4. Heavy hydrocarbon distribution, Hole 298. 


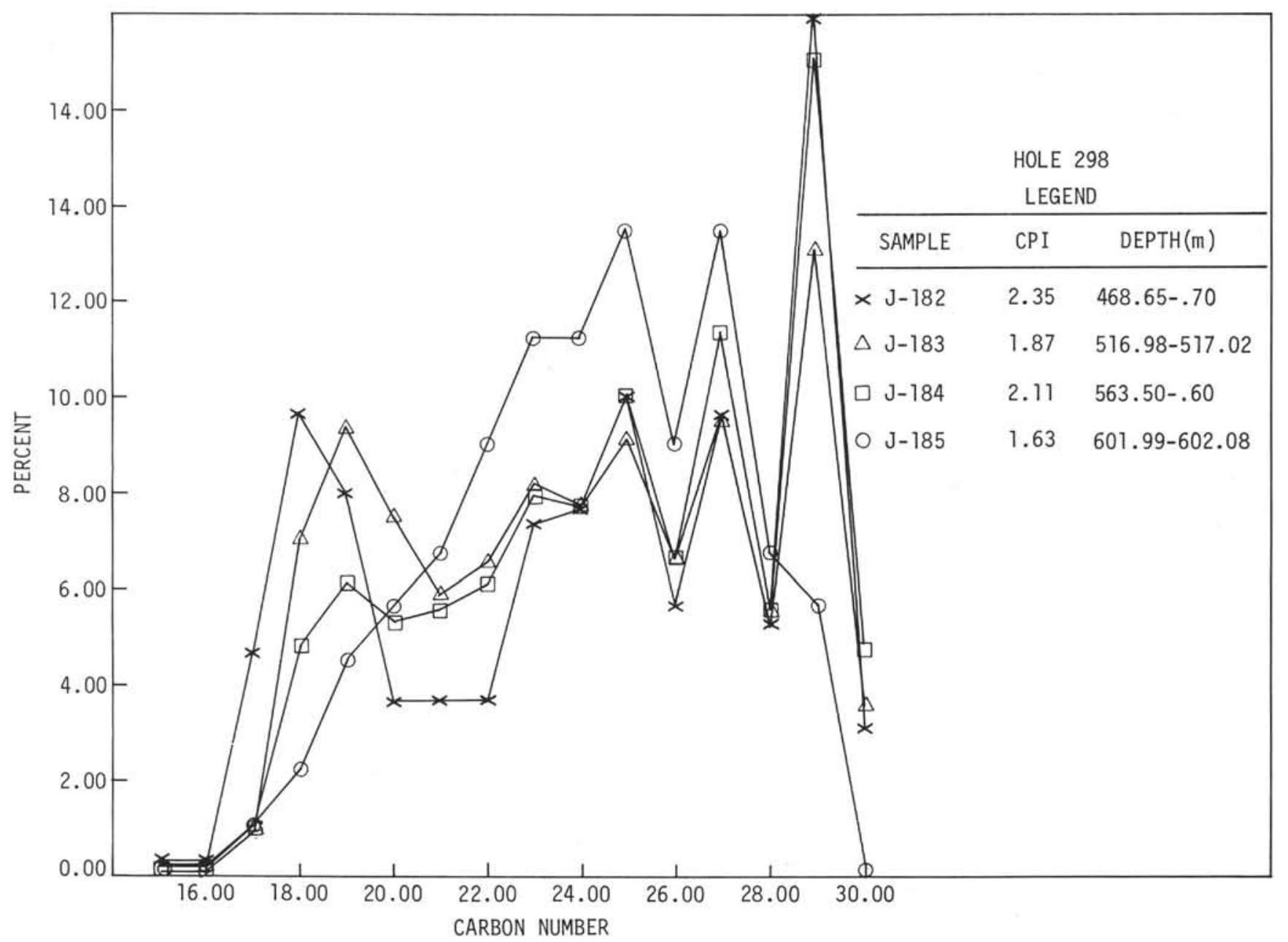

Figure 5. Heavy hydrocarbon distribution, Hole 298. 


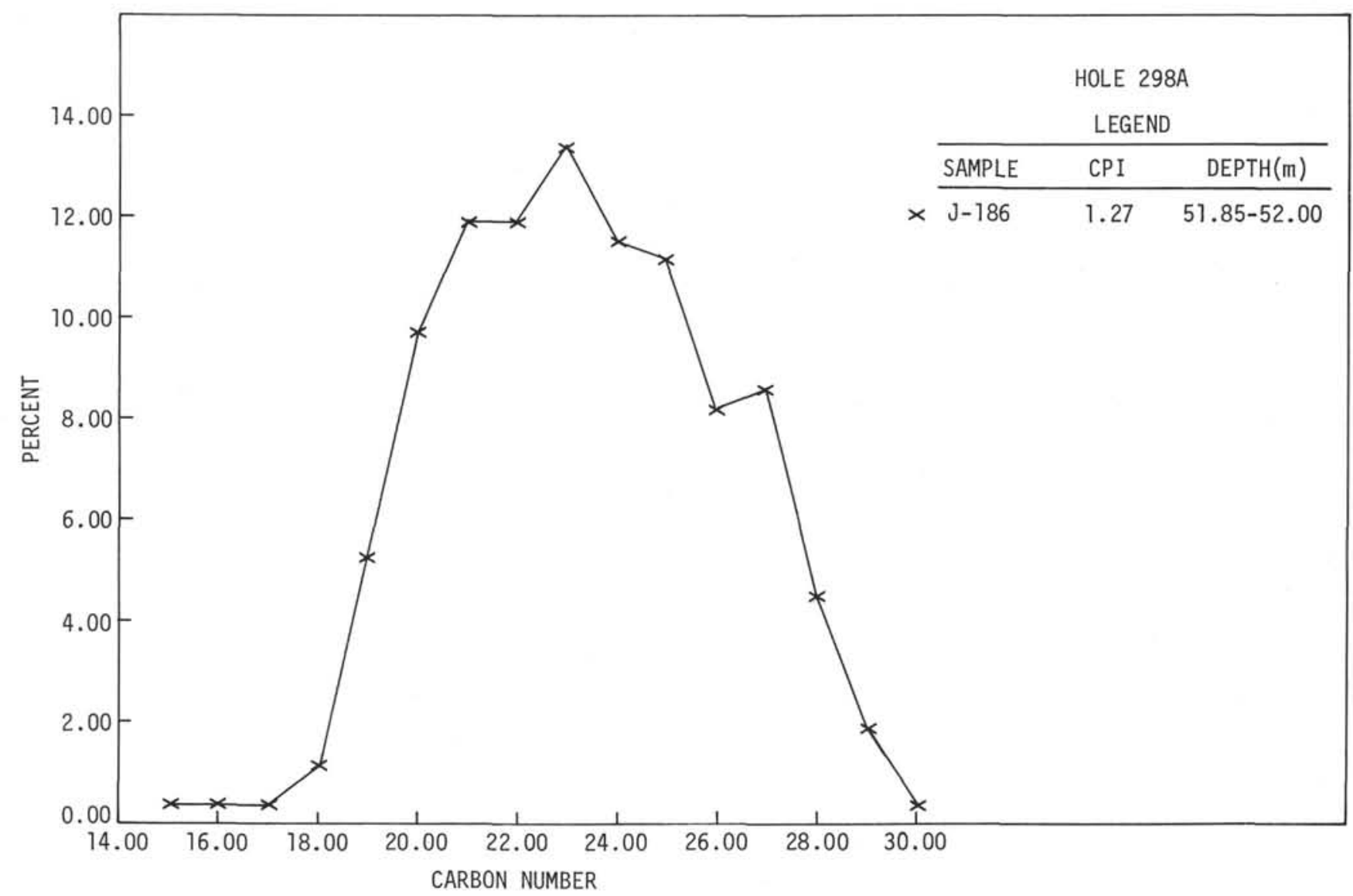

Figure 6. Heavy hydrocarbon distribution, Hole 298 A.

TABLE 2

Elemental Analysis, H/C Ratio, State of Diagenesis, and Colonization Scale of Kerogen, Holes 297, 298, and 298A

\begin{tabular}{|c|c|c|c|c|c|c|c|c|c|c|c|c|}
\hline \multirow{2}{*}{\multicolumn{2}{|c|}{ Sample }} & \multirow[b]{3}{*}{ Age } & \multirow[b]{3}{*}{ Lithology } & \multirow[b]{3}{*}{ Depth $(m)$} & \multirow{2}{*}{\multicolumn{4}{|c|}{ Elemental Analysis (\%) }} & \multirow[b]{3}{*}{ Ratio $\mathrm{H} / \mathrm{C}$} & \multirow[b]{3}{*}{ State of Diagenesis } & \multicolumn{2}{|c|}{ Hydrocarbon Type by } \\
\hline & & & & & & & & & & & \multirow[b]{2}{*}{ \% Hydrogen } & \multirow{2}{*}{$\begin{array}{c}\text { Vis. Carb } \\
\text { Scale }\end{array}$} \\
\hline Number & Type & & & & Carbon & Hydrogen & Oxygen & Nitrogen & & & & \\
\hline \multicolumn{13}{|l|}{ Hole 297} \\
\hline$J-167$ & $\mathrm{CR}$ & Pleist.-late Plio. & Mud & $201.21-0.30$ & 76.6 & 2.8 & 18.2 & 2.5 & 0.44 & Early & & 2 \\
\hline $\mathrm{J}-170$ & $\mathrm{CR}$ & Late-early Plio. & Silt & $429.43-0.60$ & 76.4 & 4.4 & 17.3 & 1.8 & 0.70 & Early & & 2 \\
\hline $\mathrm{J}-171$ & CR & Holo-late Pleist. & Mud & $128.70-0.80$ & 75.9 & 2.5 & 20.0 & 1.6 & 0.40 & Early & & 2 \\
\hline $\mathrm{J}-172$ & $\mathrm{CR}$ & Late-early Pleist. & Mud & $175.23-0.37$ & 72.7 & 3.8 & 21.4 & 2.1 & 0.63 & Early & & 2 \\
\hline$J-173$ & CR & Late-early Pleist. & Mudcarb & $185.80-0.90$ & 73.6 & 3.6 & 20.6 & 2.2 & 0.58 & Early & & 2 \\
\hline $\mathrm{J}-174$ & CR & Late-early Pleist. & Mud & $194.40-0.50$ & 74.6 & 4.2 & 19.3 & 2.0 & 0.67 & Early & & 2 \\
\hline $\mathrm{J}-175$ & $\mathrm{CR}$ & Late-early Pleist. & Mudcarb & $278.60-0.65$ & 70.2 & 3.1 & 24.9 & 1.7 & 0.53 & Early & & 2 \\
\hline J-176 & CR & Late-early Pleist. & Claystone & $297.50-0.70$ & 82.6 & 4.2 & 10.7 & 2.4 & 0.61 & Early & & 3 \\
\hline J-177 & CR & Late-early Pleist. & Claystone & $317.77-0.90$ & 75.1 & 4.2 & 18.3 & 2.4 & 0.67 & Early & & 3 \\
\hline J-178 & $\mathrm{CR}$ & Late-early Pleist. & Claystone & $337.00-0.09$ & 74.8 & 4.3 & 18.3 & 2.6 & 0.69 & Early & & 3 \\
\hline J-179 & CR & Late-early Pleist. & Mud & $364.14-0.17$ & 77.8 & 3.7 & 16.2 & 2.3 & 0.58 & Early & & 3 \\
\hline$J-180$ & CR & Late-early Pleist. & Mudcarb & $393.72-0.75$ & 75.5 & 3.5 & 18.7 & 2.2 & 0.56 & Early & & 3 \\
\hline $\mathrm{J}-181$ & CR & Late-early Pleist. & Mudcarb & $422.12-0.20$ & 76.3 & 4.1 & 17.2 & 2.4 & 0.65 & Early & & 3 \\
\hline J-182 & $\mathrm{CR}$ & Late-early Pleist. & Mudcarb & $468.65-0.70$ & 76.9 & 4,6 & 15.5 & 3.0 & 0.72 & Early & & 3 \\
\hline $\mathrm{J}-183$ & $\mathrm{CR}$ & Late-early Pleist. & Mudcarb & $516.98-517.02$ & 76.6 & 4.3 & 16.5 & 2.5 & 0.67 & Early & & 3 \\
\hline J-184 & $\mathrm{CR}$ & Late-early Pleist. & Mudcarb & $563.50-0.60$ & 77.4 & 4.2 & 15.7 & 2.7 & 0.65 & Early & & 2 \\
\hline J-185 & CR & Late-early Pleist. & Mudcarb & $601.99-602.08$ & 79.0 & 4.5 & 14.2 & 2.4 & 0.68 & Early & & 2 \\
\hline \multicolumn{13}{|c|}{ Hole 298A } \\
\hline J-186 & CR & Holo-late Pleist. & Mud & $51.85-52.00$ & 77.9 & 3.6 & 16.2 & 2.3 & 0.56 & Early & & 2 \\
\hline
\end{tabular}

${ }^{a}$ Visual carbonization scale of kerogen determined by R. Littlejohn. 


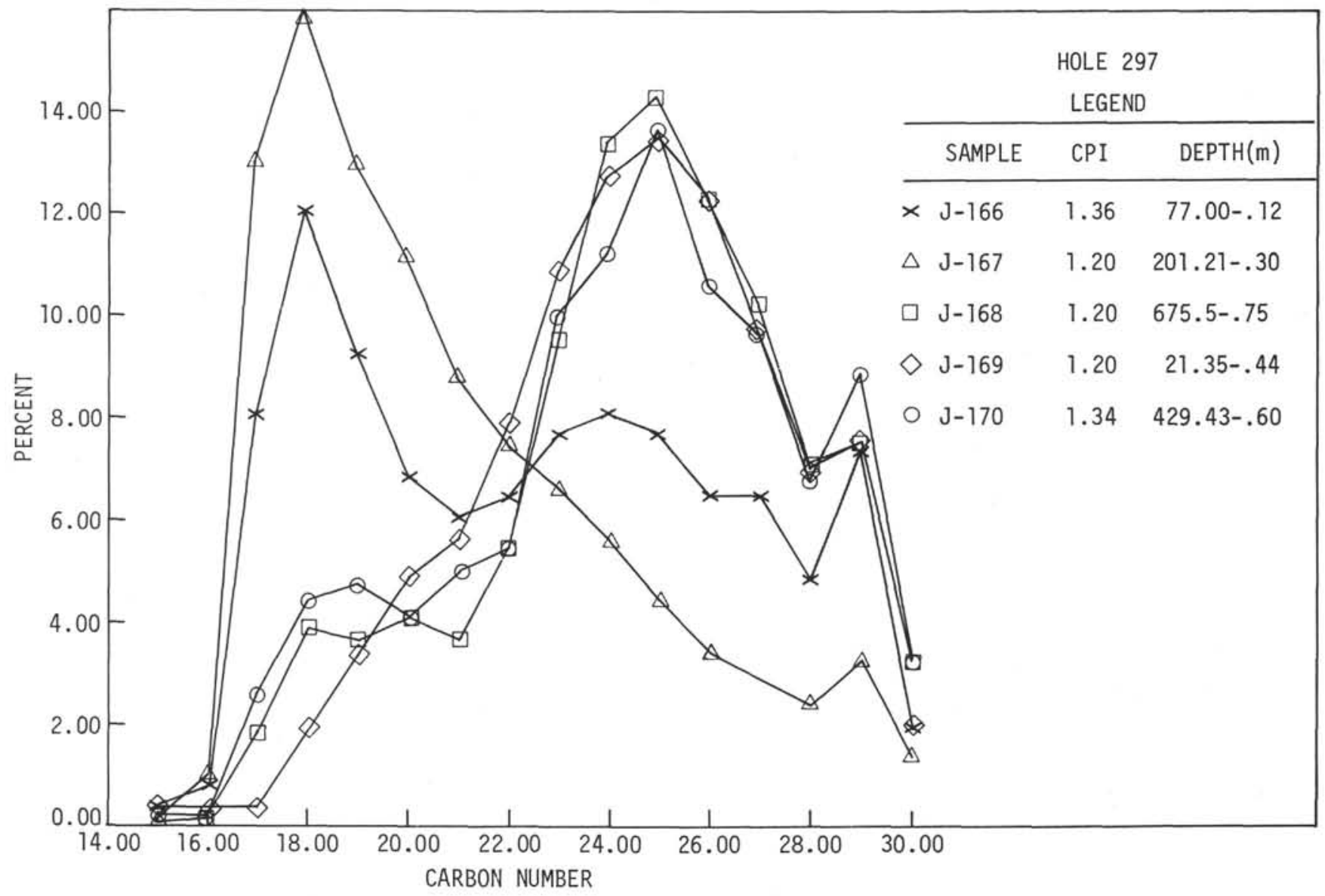

Figure 7. Heavy hydrocarbon distribution, Hole 297. 